\title{
Aplikasi mobile berbasis android sebagai media tes prior knowledge mahasiswa biologi
}

\author{
Ifa Muhimmatin *, Iis Ni'matul Jannah \\ Universitas 17 Agustus 1945 Banyuwangi. Jl. Laksda Adi Sucipto, Banyuwangi, Jawa Timur 68416, Indonesia \\ * Coressponding Author. E-mail: ifa.muhimmatin@untag-banyuwangi.ac.id
}

Received: 8 September 2020; Revised: 8 December 2020; Accepted: 3 March 2021

\begin{abstract}
Abstrak: Penelitian ini bertujuan mengembangkan sebuah aplikasi mobile berbasis android yang dapat digunakan sebagai media tes prior knowledge mahasiswa di mata kuliah sistematika tumbuhan. Aplikasi tersebut dinamakan SISTA. Pengembangan SISTA mengikuti model pengembangan 4D yang terdiri dari tahap define, design, develop, dan disseminate. Development software yang digunakan dalam mengembangkan SISTA adalah MIT App Inventor 2 Ultimate versi 4.6. Subyek uji meliputi ahli pembelajaran, ahli media, ahli IT, dan mahasiswa dari tiga angkatan berbeda. Pengumpulan data penelitian menggunakan angket, wawancara, dan tes. Teknik analisis data yang digunakan ialah persentase dan rerata. Hasil penelitian menunjukkan bahwa SISTA dinyatakan valid dan dapat digunakan sebagai media tes prior knowledge mahasiswa. Hal ini berdasarkan asil validasi ahli yang menunjukkan persentase $96,19 \%$. Hasil uji keterbacaan oleh mahasiswa terhadap SISTA juga menunjukkan persentase 90,27\% sehingga dapat dinyatakan bahwa SISTA valid tanpa revisi. Uji penerapan SISTA di kegiatan pembuka pada mata kuliah sistematika tumbuhan juga menunjukkan bahwa SISTA dapat digunakan sebagai media tes prior knowledge. SISTA sebagai media tes berbasis android memberikan kenyamanan bagi mahasiswa dalam mengerjakan tes, dan memberikan kemudahan bagi pengajar untuk menerima serta menganalisis hasil tes mahasiswa.
\end{abstract}

Kata Kunci: pengembangan, aplikasi android, prior knowledge

\section{Mobile App android-based as prior knowledge test media for biology undergraduate students}

\begin{abstract}
This paper discusses developing an android-based mobile application that can be used as a medium for testing students' prior knowledge in the plant systematics course. That application is named SISTA. The development of SISTA follows the $4 D$ development model, which consists of defining, designing, developing and disseminating stages. The development software used is MIT App Inventor 2 Ultimate version 4.6. The subjects included learning experts, media experts, IT experts, and students from three different grades. The research data was collected using questionnaires, interviews, and tests. The data analysis technique uses percentages and mean. This study showed that SISTA was declared valid and could be used as a medium for a student's prior knowledge test. This is based on the result of expert validation which shows $96.19 \%$. The results of the student readability test for SISTA also showed $90.27 \%$, so it could be stated that SISTA is valid without revision needed. The test of the application of SISTA in the opening activity in the plant systematics course also shows that SISTA can be used as a medium for testing prior knowledge. SISTA is an androidbased test media that provides comfort for students and benefits teachers to accept and analyze student test results.
\end{abstract}

Keywords: development, android App, prior knowledge

How to Cite: Muhimmatin, I., \& Jannah, I. (2021). Aplikasi mobile berbasis android sebagai media tes prior knowledge mahasiswa biologi. Jurnal Inovasi Pendidikan IPA, 7(1), 1-11. doi:https://doi.org/10.21831/jipi.v7i1.34335

\section{PENDAHULUAN}

Prior Knowledge merupakan pengetahuan awal yang dimiliki oleh manusia sebelum ia memperoleh pengetahuan baru (Kujawa \& Huske, 1995). Pengetahuan tersebut terus berkembang seiring dengan pengalaman sehari-hari (Suma et al., 2018). Prior knowledge tidak hanya berkaitan dengan pengetahuan saja, namun juga berkaitan dengan perilaku dan pengalaman siswa (Hailikari, 2009). Dalam proses pem- 
belajaran, prior knowledge berfungsi dalam konteks asimilasi informasi, dimana materi yang diterima kemudian terkait dengan pengetahuan dan ketrampilan yang telah dimiliki oleh siswa, sehingga pengetahuan baru mudah dikonstruksi secara elaborative (Baek et al., 2015).

Prior knowledge dapat meningkatkan proses memori secara signifikan, menyediakan sebuah dorongan untuk belajar, yang kemudian dapat mendorong mahasiswa dalam perolehan pengetahuan baru (Shing \& Brod, 2016; Wade \& Kidd, 2019). Prasyarat pengaruh positif prior knowledge tersebut terhadap pengetahuan baru adalah adanya keterhubungan antara pengetahuan yang baru dengan pengetahuan yang lama (Baek et al., 2015). Jadi, prior knowledge dapat berpengaruh terhadap prestasi siswa selama prior knowledge siswa tersebut berhubungan dengan informasi baru yang diperoleh.

Pembelajaran sistematika tumbuhan di program studi pendidikan biologi Untag Banyuwangi menuntut mahasiswa mempunyai prior knowledge berupa pengetahuan tentang morfologi dan anatomi tumbuhan. Kedua kajian tersebut telah dipelajari mahasiswa di semester sebelumnya, sehingga seharusnya mahasiswa mempunyai prior knowledge yang memadai. Namun pada prakteknya, pembelajaran sistematika tumbuhan sering terhambat karena prior knowledge mahasiswa yang bervariasi. Padahal, prior knowledge menjadi modal bagi pebelajar dalam menerima dan mengorganisasi informasi baru (Pamungkas et al., 2017; Svinicki, 2012). Jika informasi yang akan dipelajari tidak konsisten dengan pra-anggapan pebelajar, maka prior knowledge dapat menghalangi perolehan pengetahuan baru (Shing \& Brod, 2016).

Mahasiswa sering mempunyai pemahaman yang kurang mantap tentang istilah dalam sistematika tumbuhan, maupun istilah dalam morfologi tumbuhan dan anatomi tumbuhan. Contohnya istilah 'familia' yang dapat dimaknai beragam oleh mahasiswa. Ada yang menjabarkannya sebagai 'sekumpulan tumbuhan yang berasal dari buah yang sama', 'dua jenis tumbuhan yang bentuknya mirip', dan familia sebagai 'suatu tingkatan takson'. Prior knowledge yang berbeda-beda ini menyebabkan tidak maksimalnya pemahaman mahasiswa secara menyeluruh (Baek et al., 2015), dan berpotensi membentuk sebuah miskonsepsi (Svinicki, 2012). Karena itulah, penting bagi pendidik untuk mengetahui prior knowledge mahasiswa, dan menyempurnakan pemahaman awal tersebut sebelum materi inti diberikan. Penerapan sebuah media yang praktis dan menyenangkan dapat menjadi solusi untuk mengukur dan memantapkan prior knowledge mahasiswa di awal kegiatan perkuliahan.

Kemajuan teknologi menyebabkan jenis media semakin beragam, semakin interaktif, dan mudah diakses. Mahasiswa sudah akrab dengan penggunaan smartphone, internet, dan berbagai aplikasi mobile. Rata-rata, penguna internet menghabiskan 4 jam 46 menit per hari untuk menggunakan smartphone (Pertiwi, 2020). Sampai dengan bulan Juni tahun 2020, tercatat telah ada sekitar 2.960 .000 aplikasi berbasis android di Google Play Store. Jumlah ini meningkat sekitar 260.000 dibanding bulan yang sama dari tahun 2019 (Clement, 2020).

Kemajuan teknologi juga memudahkan pendidik yang tidak menguasai bahasa pemograman "tradisional" seperti C++, Java, atau Kotlin untuk dapat mengembangkan aplikasi mobile sendiri. Scratch, Star Logo, App Inventor, Thunkable, Appybuilder, Makeroid, dan Blokly merupakan beberapa contoh development software yang dapat digunakan oleh pendidik untuk mengembangkan media pembelajaran berbasis android. Development software tersebut memiliki friendly interface yang memudahkan penggunanya dalam melakukan koding (Hsu et al., 2012).

Pesatnya inovasi aplikasi mobile ini, serta fleksibilitas dan kreativitasnya yang tidak dimiliki oleh media pembelajaran konvensional, meningkatkan animo pendidik untuk menggunakan aplikasi dalam proses pembelajaran di kelas (Johnson \& Cummins, 2012). Contoh aplikasi mobile yang kini secara luas telah dimanfaatkan sebagai media pembelajaran di Indonesia misalnya ruangguru, quipper, dan lain sebagainya. Penggunaan aplikasi mobile sebagai media pembelajaran mempunyai dampak positif terhadap siswa (Sholihah et al., 2020). Selain itu, penerapan aplikasi android terbukti dapat meningkatkan pemahaman dan antusiasme siswa dalam belajar (Safitri et al., 2019; A. S. Sari et al., 2020). Melalui penelitian oleh Hsu dan Ching (2013), terbukti bahwa animo pengajar non-programmer dalam mengembangkan aplikasi pembelajaran juga tergolong tinggi.

Aplikasi mobile berbasis android tak pelak menjadi salah satu media yang menarik untuk digunakan dalam pembelajaran. Hal ini sesuai dengan meta-analisis yang dilakukan oleh Surata et al., (2020) bahwa multimedia merupakan media pembelajaran yang paling efektif, dengan spesifikasi daring, blended, atau berbasis android sehingga lebih mudah diakses oleh pebelajar. Melalui beberapa penelitian, telah dibuktikan bahwa penerapan media mobile berbasis aplikasi android dapat meningkatkan aktivitas siswa pada proses pembelajaran (Widiansyah et al., 2018), dan meningkatkan antusiasme siswa 
(A. M. Sari \& Nurcahyo, 2018). Selain itu, penerapan media mobile dapat menghemat biaya, mengurangi penggunaan kertas, dan mendukung pembelajaran jarak jauh (Hermawan et al., 2017). Hal ini sesuai dengan kegiatan pendidikan di masa pandemic yang mengharuskan kegiatan pembelajaran di perguruan tinggi dilaksanakan secara jarak jauh.

Diantara kajian tentang pengembangan aplikasi berbasis android dalam pendidikan, mayoritas berfokus pada pengembangan aplikasi android sebagai media untuk meningkatkan proses dan hasil belajar. Sedangkan pengembangan media berbasis android sebagai media tes masih minim, sehingga penelitian ini berfokus pada usaha pengembangan aplikasi mobile berbasis android sebagai media tes prior knowledge mahasiswa di mata kuliah sistematika tumbuhan.

Tes prior knowledge dapat digunakan untuk mengindentifikasi kesulitan belajar, menentukan tingkat kesulitan materi yang diberikan, menjembatani perbedaan antara tujuan pembelajaran yang ingin dicapai pendidik dengan kenyataan kemampuan siswa, serta menentukan antisipasi pemahaman siswa terhadap materi yang diberikan (Hailikari et al., 2008). Tujuan yang disebutkan terakhir menjadi alasan perlunya pengembangan sebuah media tes berbasis android yang dapat mengukur sekaligus memantapkan prior knowledge mahasiswa, sebelum memasuki materi inti.

Penelitian ini bertujuan mengembangkan sebuah aplikasi mobile berbasis android dalam format APK yang dapat digunakan sebagai media prior knowledge's test mahasiswa di Mata Kuliah Sistematika Tumbuhan. Aplikasi mobile berbasis android ini selain dapat digunakan untuk menguji prior knowledge, juga dapat menjadi media belajar yang menyenangkan di awal sesi perkuliahan.

\section{METODE}

Penelitian ini adalah penelitian pengembangan (design-based research) untuk menghasilkan media tes prior knowledge untuk mahasiswa berupa aplikasi mobile berbasis android. Aplikasi hasil pengembangan ini diberi nama SISTA: a prior knowledge quiz. Tahapan pengembangan SISTA mengikuti model pengembangan 4D Thiagarajan et al., (1974) yang meliputi tahap define, design, develop, dan disseminate. Model pengembangan 4D dipilih karena tahapannya sesuai untuk mengembangkan media pembelajaran dan di setiap tahapnya diikuti oleh proses revisi.

Tahap pertama model 4D ialah tahap define, yang berisi analisis kebutuhan terhadap aplikasi. Analisis yang dilakukan pada tahap ini adalah analisis ujung depan, analisis mahasiswa, analisis tugas, analisis konsep, dan penentuan tujuan pembelajaran. Hasil analisis pada tahap define ini kemudian menjadi pertimbangan utama untuk pelaksanaan tahap design.

Tahap kedua adalah tahap mendesain user interface dan koding aplikasi SISTA. Development software yang digunakan untuk mengembangkan SISTA adalah App Inventor 2 Ultimate versi 4.6 yang dikembangkan oleh Google Inc. bekerjasama dengan Massachusetts Institute of Technology (MIT) California. Hasil tahap kedua ini berupa prototype SISTA yang dapat diinstal di smartphone berbasis android minimal versi 2.2 .

Tahap ketiga adalah tahap develop, yakni menguji prototype SISTA melalui dua uji. Uji pertama ialah uji validasi prototype SISTA yang dilakukan oleh ahli IT, ahli media, dan ahli pembelajaran. Ahli IT adalah tenaga TIK di SMP negeri, berpendidikan terakhir S2 bidang pendidikan, dan pemilik toko komputer. Ahli media adalah dosen pengampu mata kuliah media pendidikan, berpendidikan terakhir S2 bidang teknologi pendidikan, dan mempunyai pengalaman dalam penelitian pengembangan. Ahli pembelajaran adalah dosen ahli evaluasi pembelajaran, berpendidikan terakhir S2 bidang pendidikan, dan mempunyai pengalaman dalam penelitian tindakan. Berdasar hasil uji validasi oleh ahli, didapat keputusan validitas prototype SISTA, dan revisi. Uji kedua ialah uji keterbacaan yang dilakukan oleh 24 mahasiswa yang telah menempuh mata kuliah sistematika tumbuhan. Aspek yang dinilai pada uji keterbacaan ini meliputi aspek aksesibilitas, tata letak, konten, instruksi, gambar, animasi, dan audio. Berdasar hasil uji keterbacaan, didapat keputusan validitas prototype SISTA, dan revisi.

Tahap keempat adalah tahap disseminate, meliputi penerapan SISTA di kelas nyata, dan penyebarluasan SISTA melalui playstore. Penerapan SISTA di kelas nyata ialah dengan menerapkan SISTA sebagai media tes prior knowledge mahasiswa. Penerapan SISTA ialah pada kegiatan pendahuluan di mata kuliah sistematika tumbuhan. Penerapan ini dilaksanakan selama tiga pertemuan yang melibatkan 17 mahasiswa. Penyebarluasan SISTA melalui playstore merupakan wujud sumbangsih agar dosen lain dapat memanfaatkan SISTA sebagai media tes prior knowledge di mata kuliah sistematika tumbuhan. 
Penelitian dilaksanakan mulai bulan Maret hingga Agustus 2020 di Universitas 17 Agustus 1945 Banyuwangi. Pengumpulan data penelitian dilakukan melalui angket, wawancara, dan tes. Instrumen yang digunakan ialah lembar validasi ahli, lembar angket keterbacaan mahasiswa, lembar panduan wawancara, dan prototype SISTA. Lembar validasi ahli digunakan untuk uji validitas prototype SISTA; lembar angket keterbacaan dan panduan wawancara diguanakan pada tahap uji keterbacaan, dan prototype SISTA digunakan pada tahap disseminate sebagai media tes prior knowledge.

Teknik analisis data yang digunakan ialah teknik analisis deskriptif kuantitatif berupa persentase dan rerata. Hasil perhitungan persentase digunakan untuk pengambilan keputusan tentang tingkat validitas SISTA dan perlu tidaknya revisi SISTA dilakukan (Tabel 1). Rerata hasil skor prior knowledge mahasiswa menunjukkan tingkat prior knowledge mahasiswa yang menggunakan SISTA, dan keputusan perlu atau tidaknya pemantapan prior knowledge sebelum mahasiswa memperoleh materi ajar baru (Tabel 2).

Tabel 1. Kriteria Tingkat Validitas SISTA dan Keputusan Revisi

\begin{tabular}{ccc}
\hline Hasil Validitas $(\%)$ & Kualifikasi & Keterangan \\
\hline $81-100$ & Sangat baik & Tidak perlu revisi/valid \\
$61-80$ & Baik & Tidak perlu revisi/valid \\
$41-60$ & Cukup & Revisi/tidak valid \\
$21-40$ & Kurang & Revisi/tidak valid \\
$0-20$ & Sangat kurang & Revisi/tidak valid \\
\hline
\end{tabular}

Tabel 2. Kriteria Tingkat Prior Knowledge Mahasiswa

\begin{tabular}{ccc}
\hline Hasil Tes Prior Knowledge $(\mathrm{x})$ & Kualifikasi & Keterangan \\
\hline $81-100$ & Sangat baik & Tidak perlu pemantapan \\
$61-80$ & Baik & Tidak perlu pemantapan \\
$41-60$ & Cukup & Perlu pemantapan \\
$21-40$ & Kurang & Perlu pemantapan \\
$0-20$ & Sangat kurang & Perlu pemantapan \\
\hline
\end{tabular}

\section{HASIL DAN PEMBAHASAN}

Hasil analisis ujung depan pada tahap define menunjukkan bahwa kemampuan awal mahasiswa di mata kuliah sistematika tumbuhan pada tahun 2019 masih rendah. Hal ini diketahui melalui uji Teslet yang terdiri dari 3 soal utama dan 3 soal pendukung, dan perhitungan skor tes menggunakan metode Graded Respon Model (GRM). Hasil tes tersebut menunjukkan bahwa hanya 31,25\% mahasiswa yang mempunyai pemahaman awal dengan skor 2 , sedangkan sisanya mempunyai skor satu dan nol. Pada tes ini juga ditemukan adanya miskonsepsi tentang unit-unit takson pada klasifikasi tumbuhan. Data hasil tes tersebut menunjukkan perlunya sebuah media tes untuk mengetahui prior knowledge mahasiswa, dan memantapkannya sebelum kegiatan inti pembelajaran sistematika tumbuhan dilaksanakan.

Hasil analisis mahasiswa menunjukkan bahwa mahasiswa telah akrab dengan penggunaan aplikasi smartphone, sehingga media tes prior knowledge dapat berupa aplikasi mobile berbasis android. Hasil analisis terhadap tema pembelajaran menunjukkan bahwa terdapat lima tema pembelajaran di mata kuliah sistematika tumbuhan yang memerlukan tes prior knowledge untuk mahasiswa (Tabel 3). Kelima tema tersebut membutuhkan prior knowledge mahasiswa yang berkaitan dengan istilah dan pemahaman tentang morfologi dan anatomi tumbuhan.

Keseluruhan hasil analisis pada tahap define ini mengukuhkan bahwa media tes harus mudah diakses oleh mahasiswa, mudah digunakan, sesuai dengan pembelajaran daring, dan benar-benar dapat mengukur prior knowledge mahasiswa di awal kegiatan perkuliahan. Hal inilah yang menjadi pengembangan SISTA sebagai media tes prior knowledge.

Tahap kedua dari pada pengembangan SISTA adalah tahap design. Tahap ini merupakan tahap mendesain aplikasi sehingga menghasilkan prototype SISTA. Pengembangan prototype SISTA dilakukan menggunakan development software dari App Inventor 2 Ultimate versi 4.6 (via AI2 Ultimate 4.6 64bit Portable dan google chrome). App Inventor dipilih sebagai development software karena kodingnya mudah dan dapat digunakan secara luring. Pengembangan aplikasi berbasis android menggunakan App Inventor 2 telah banyak dilakukan, salahsatunya oleh Asghar et al., (2016) yang mengembangkan aplikasi tes pilihan ganda untuk persiapan ujian masuk di bidang komputer sains. Jadi, 
Jurnal Inovasi Pendidikan IPA, 7 (1), 2021 - 5

Ifa Muhimmatin, Iis Ni'matul Jannah

App Inventor memang sesuai untuk dijadikan sebagai development software dalam pengembangan SISTA.

Tabel 3. Hasil Analisis Kebutuhan terhadap penerapan SISTA di tiap Topik

\begin{tabular}{clc}
\hline Pertemuan & \multicolumn{1}{c}{ Tema } & Penerapan SISTA \\
\hline 1 & Lingkup sistematika tumbuhan rendah & $\mathrm{x}$ \\
2 & Takson dan Tatanama Tumbuhan & $\mathrm{X}$ \\
3 & Sejarah Klasifikasi Tumbuhan & $\mathrm{x}$ \\
4 & Macam Sistem Klasifikasi Tumbuhan & $\checkmark$ \\
5 & Sistem Klasifikasi 5 Kingdom & $\mathrm{X}$ \\
6 & Algae (ciri, reproduksi, klasifikasi, manfaat) & $\mathrm{x}$ \\
7 & Lichenes (ciri, reproduksi, klasifikasi, manfaat) & $\mathrm{x}$ \\
8 & Bryophyta 1 (ciri, Reproduksi dan metagenesis) & $\checkmark$ \\
9 & Bryophyta 2 (klasifikasi dan manfaat) & $\checkmark$ \\
10 & Pteridophyta 1 (ciri, reproduksi, dan metagenesis) & $\mathrm{x}$ \\
11 & Pteridophyta 2 (klasifikasi) & $\checkmark$ \\
12 & Pteridophyta 3 (klasifikasi dan peranan) & $\mathrm{x}$ \\
13 & Ptridophyta 4 (around us) & $\mathrm{x}$ \\
14 & Laporan, review, \& refleksi & \\
\hline
\end{tabular}

Proses penyusunan SISTA dimulai dengan menyusun story board berdasar hasil analisis di tahap define, kemudian membuat animasi, gambar, dan video. Adapun animasi, gambar, dan video tersebut diolah terlebih dahulu menggunakan software CorelDRAW dan Adobe Photoshop, sedangkan video dan audio diolah menggunakan OBS Studio, Wondershare Filmora9, dan Microsoft Office. Sinergi dari penggunaan bermacam software ini menghasilkan tampilan SISTA yang sesuai dengan peruntukannya sebagai media tes. Langkah berikutnya yakni menyusun user interface SISTA dan memasukkan berbagai gambar, animasi, serta video yang telah diolah. Langkah terakhir pada tahap ini ialah menyusun koding agar semua instruksi dan tombol pada menu SISTA dapat berfungsi. Hasil dari proses penyusunan ini adalah prototype SISTA, dengan tampilan seperti terlihat pada Gambar 1.

Aplikasi SISTA berisi menu utama, menu instruksi, menu tes; menu skor hasil tes; dan pembahasan soal. Isi dari aplikasi SISTA ini sesuai dengan fungsinya sebagai media tes prior knowledge. Pada menu utama terdapat lima chapter, hal ini sesuai dengan pemetaan tema perkuliahan yang memerlukan tes prior knowledge. User interface pada menu utama SISTA disusun sederhana dengan dominan warna hijau, dengan tombol yang mudah diakses dengan jari. Pada menu tes dilengkapi dengan countdown timer agar mahasiswa mengerjakan tes dengan optimal. Setiap tes terdiri dari 7 hingga 12 soal dengan level $\mathrm{C} 1$ hingga $\mathrm{C} 3$ pada taksonomi Bloom. Menu skor tes dilengkapi dengan animasi dan audio sesuai hasil skor tes mahasiswa, sebagai bentuk apresiasi pada hasil tes mahasiswa. Menu skor terhubung dengan google spreadsheet sehingga skor mahasiswa langsung terkirim ke dosen secara realtime sesaat setelah mahasiswa mengerjakan tes. Menu terakhir pada SISTA adalah menu review. Menu ini berisi teks, gambar, dan video animasi yang disertai dengan audio penjelasan. Hasil tahap design ini berupa prototype SISTA dalam format Apk yang siap diinstall di gawai berbasis android.
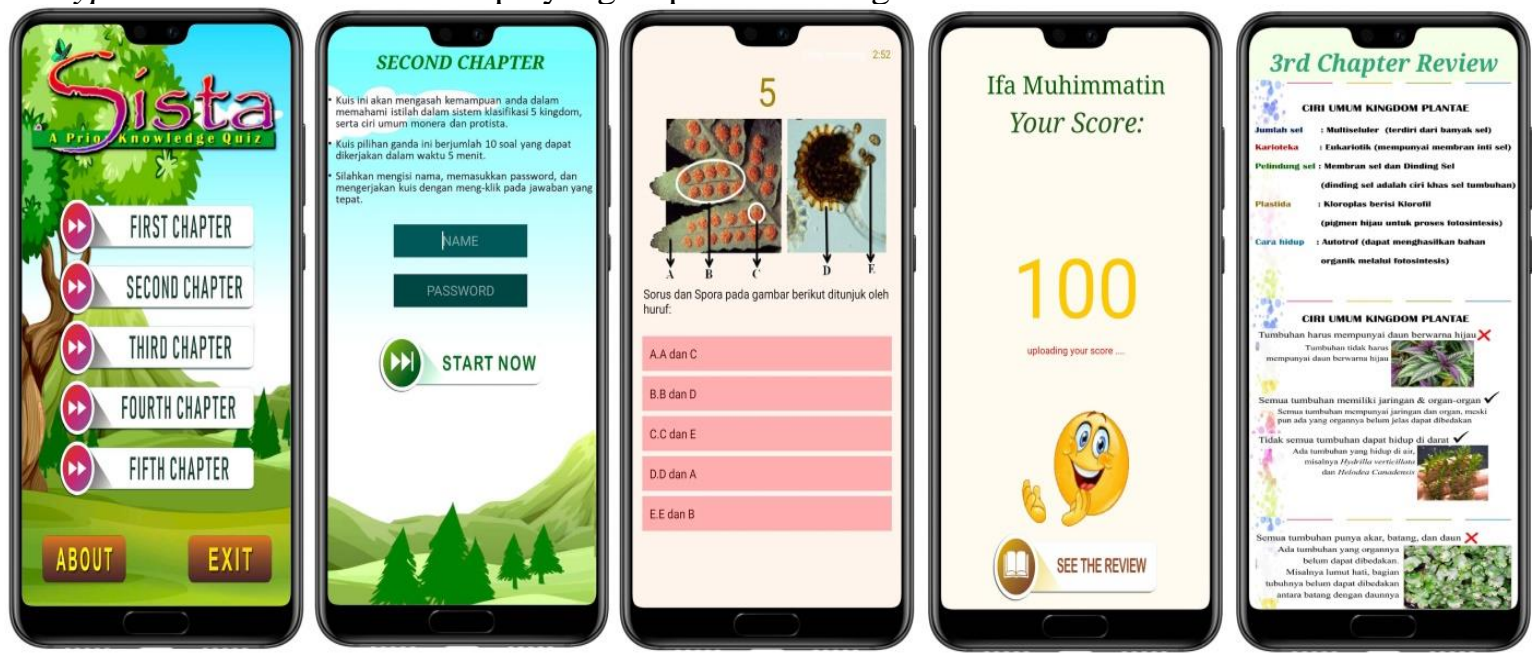

Gambar 1. Tampilan SISTA 
Tahap ketiga pada pengembangan SISTA adalah tahap develop. Pengembangan prototype SISTA menerapkan prinsip mudah diakses, efektif, menarik, dan relevan dengan fungsinya sebagai media tes prior knowledge di mata kuliah sistematika tumbuhan. Untuk memenuhi tujuan tersebut, prototype SISTA diuji validitasnya oleh tiga ahli, yakni ahli pembelajaran, ahli media, dan ahli IT. Aspek penilaian validasi ahli meliputi relevansi, konsistensi, praktik, desain, bahasa, dan kebermanfaatan (Gambar 2). Aspek validasi ini dikembangkan berdasar kriteria yang dikemukakan oleh Nieveen \& Folmer, (2013). Uji validitas menggunakan instrumen angket validasi yang berisi 42 pernyataan uji.

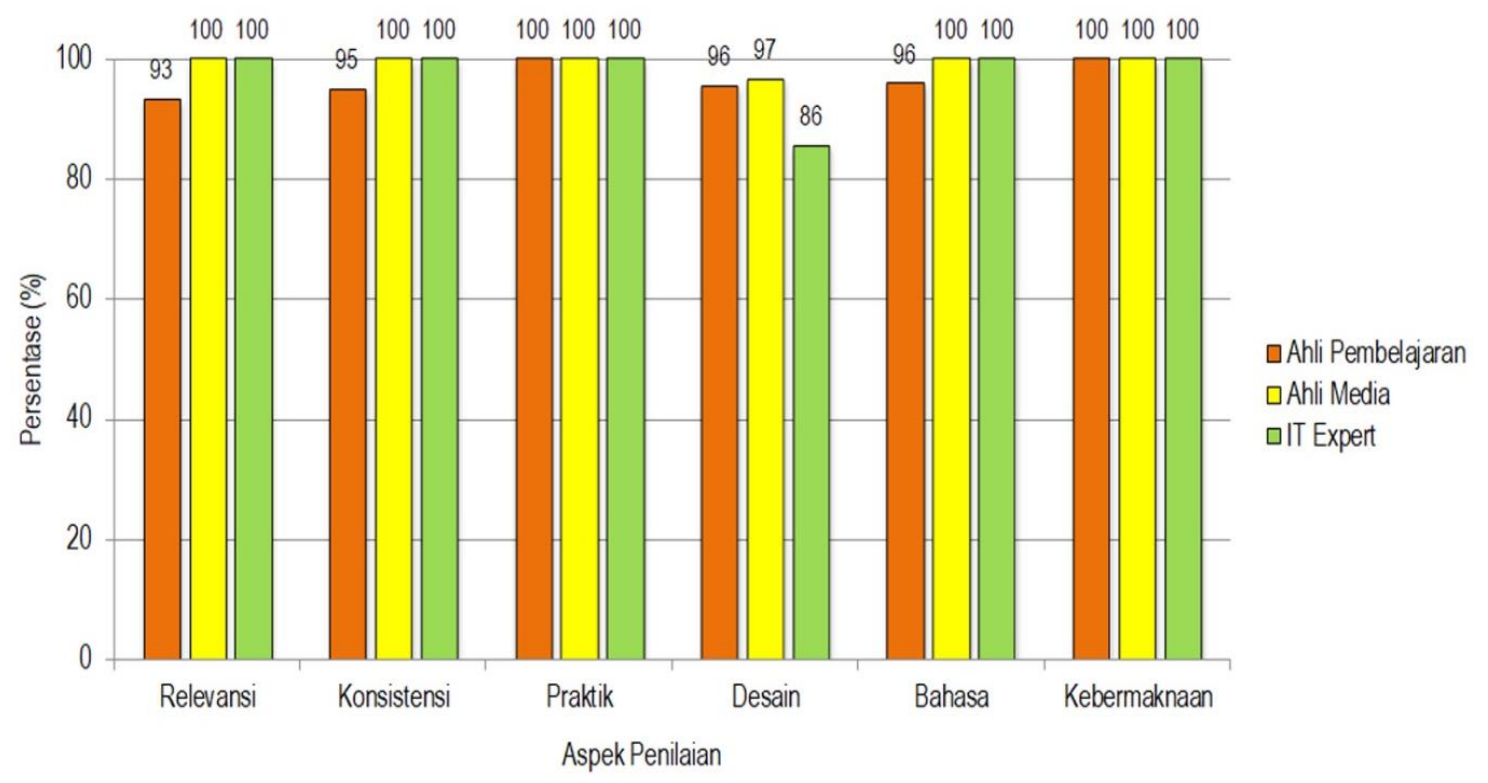

Gambar 2. Persentase Hasil Validasi Ahli di tiap Aspek Penilaian

Hasil validasi ahli menunjukkan bahwa aspek yang mendapat skor tinggi adalah aspek praktik, kebermanfaatan, aspek bahasa, dan aspek konsistensi. Sedangkan aspek desain mempunyai skor paling rendah, terutama dari penilaian ahli IT. Hal ini karena ukuran animasi dan teks yang tidak proporsional ketika SISTA diinstall pada gawai yang berbeda. Kemudian terdapat istilah yang kurang tepat yang diucapkan oleh narrator pada video tentang Bryophyta. Berdasar masukan tersebut, dilakukan beberapa revisi. Animasi dan teks di koding ulang sehingga teks dan animasi dapat muncul secara proporsional di berbagai ukuran layar dan tipe smartphone. Narasi pada penjelasan tentang Bryophyta pada video juga diperbaiki.

Ringkasan hasil validasi prototype SISTA oleh ahli tersaji di tabel 4. Hasil validasi oleh ahli media adalah 98,57\% dan merupakan persentase tertinggi, sedangkan validasi oleh ahli IT adalah yang paling rendah dengan persentase $93,81 \%$. Hasil validasi ahli secara keseluruhan menunjukkan persentase $96,19 \%$ sehingga dapat diputuskan bahwa aplikasi SISTA valid sebagai media tes prior knowledge, dan tidak perlu dilakukan revisi.

Tabel 4. Hasil Validasi Ahli

\begin{tabular}{ccccc}
\hline Ahli Pembelajaran & Ahli Media & Ahli IT & Rerata & Keputusan \\
\hline $96,19 \%$ & $98,57 \%$ & $93,81 \%$ & $96,19 \%$ & Valid, tidak perlu revisi \\
\hline
\end{tabular}

Uji kedua pada tahap develop adalah uji keterbacaan. Uji ini dilakukan terhadap mahasiswa yang telah menempuh mata kuliah sistematika tumbuhan. Aspek uji keterbacaan meliputi aspek aksesibilitas, tata letak, konten, instruksi, gambar, animasi, dan aspek audio. Jumlah pernyataan untuk keseluruhan aspek tersebut ialah 22 butir pernyataan. Hasil uji keterbacaan tersaji pada Gambar 3.

Persentase hasil uji keterbacaan ialah 90,27\% sehingga dapat dinayatakan bahwa SISTA valid dan tidak perlu revisi. Berdasar hasil uji keterbacaan, aspek yang mendapat skor tinggi adalah aspek aksesibilitas, aspek animasi, dan aspek audio. Mahasiswa berpendapat bahwa SISTA merupakan alat tes yang menarik, menyenangkan, dan sesuai digunakan dalam pembelajaran jarak jauh. SISTA dapat diakses dengan mudah melalui smartphone masing-masing mahasiswa, dan skor hasil tes pun otomatis terkirim ke dosen. Hal ini sejalan dengan pendapat bahwa dengan penerapan aplikasi berbasis android, ruang dan waktu bukan lagi penghalang bagi proses pembelajaran (Ali \& Ahmad, 2014; Walsh, 2015). 
Dengan aplikasi mobile, belajar dapat dilakukan di mana pun dan kapan pun dengan cara yang mudah, sederhana melalui aplikasi di smartphone masing-masing (Dasmo et al., 2017).

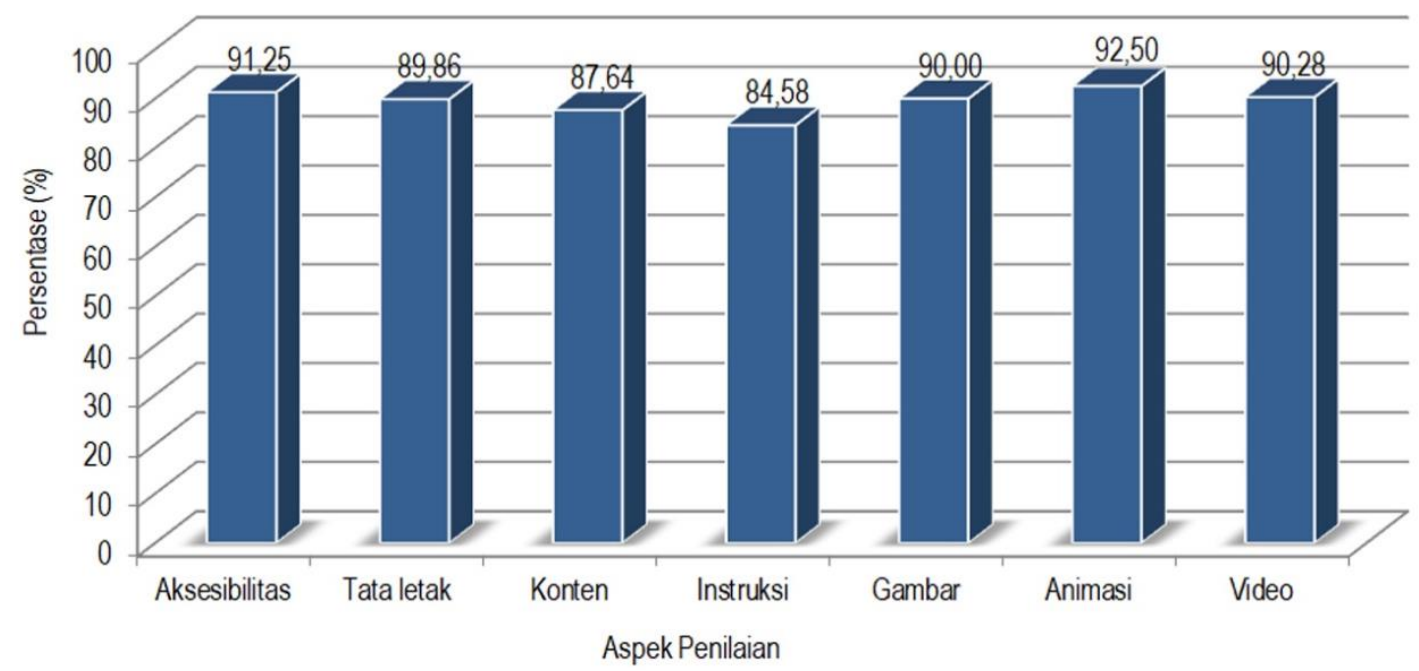

Gambar 3. Persentase Hasil Uji Keterbacaan di tiap Aspek Penilaian

Namun, hasil wawancara menemukan adanya kekurangan pada SISTA. Menurut mahasiswa, instruksi tes pada SISTA berbentuk paragraf panjang sehingga sulit dipahami. Hal ini karena kemampuan mahasiswa berbeda-beda dalam memahami instruksi tes. Berdasar masukan tersebut, instruksi tes pada SISTA dibuat dalam bentuk poin, dengan pemilihan kata yang tepat sehingga instruksi tes lebih mudah dipahami.

Tahap terakhir dari tahap pengembangan 4D ialah tahap disseminate, yakni dengan menerapkan SISTA pada kelas sesungguhnya. SISTA diterapkan pada pembelajaran mata kuliah sistematika tumbuhan yang dilaksanakan secara daring mulai bulan Mei hingga Juni 2020. Penerapan SISTA dilaksanakan di tiga pertemuan, dan SISTA diterapkan di awal kegiatan pembelajaran sebagai media tes prior knowledge mahasiswa.

Pada penerapan ini, setelah perkuliahan dimulai, mahasiswa diinstruksikan untuk melakukan tes prior knowledge melalui aplikasi SISTA. Setelah mahasiswa mengerjakan tes, dosen menerima hasil tes secara realtime dari aplikasi. Berdasar hasil tes tersebut, dosen dapat menentukan tingkat prior knowledge mahasiswa, dan memantapkannya sebelum perkuliahan inti dimulai. Rerata hasil tes prior knowledge mahasiswa tersaji pada Gambar 4.

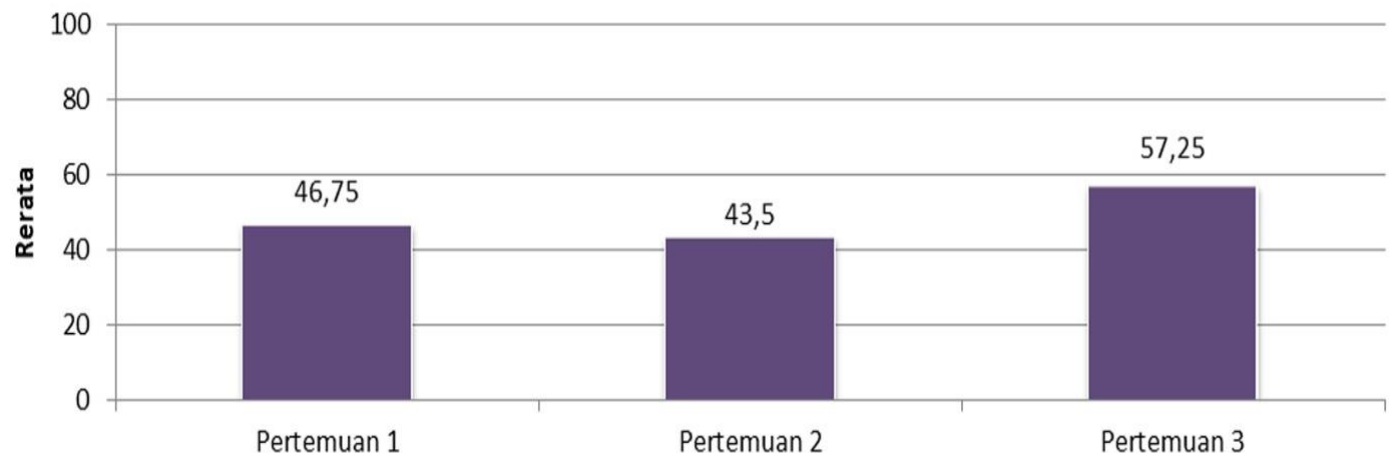

Tes Prior Knowledge di -

Gambar 4. Rerata Prior Knowledge Mahasiswa selama 3 Pertemuan

Hasil penerapan SISTA yang pertama menunjukkan rerata skor 46,75 dari skor total 100. Rerata ini menunjukkan bahwa prior knowledge mahasiswa dalam kategori cukup, dan membutuhkan pemantapan prior knowledge sebelum kegiatan inti dilakukan (sesuai kriteria pada Tabel 2). Hal ini juga terjadi pada penerapan SISTA yang kedua dan ketiga. Artinya, prior knowledge mahasiswa masih rendah sehingga dapat menimbulkan miskonsepsi jika prior knowledge tersebut tidak dimantapkan terlebih dahulu. Hasil tes SISTA ini menunjukkan bahwa miskonsepsi juga dapat terjadi pada mahasiswa calon 
guru. Temuan ini sesuai dengan hasil penelitian Dewi et al. (2019) yang menyatakan bahwa kecenderungan untuk terjadinya miskonsepsi pada mahasiswa calon guru sains terhadap konsep respirasi seluler masih tinggi. Pemantapan prior knowledge dilakukan dengan menginstruksikan mahasiswa untuk membaca atau memahami video pada SISTA, kemudian dikonfirmasi secara oral selama pembelajaran daring.

Penerapan SISTA di mata kuliah sistematika tumbuhan memberikan pengalaman kepada mahasiswa untuk melakukan tes prior knowledge secara menyenangkan. Mahasiswa menyatakan bahwa mereka antusias menggunakan SISTA karena mudah digunakan dan dengan sekali klik langsung masuk ke menu SISTA. Mahasiswa juga mengapresiasi pembahasan yang disajikan dengan teks, gambar, dan video. Hal ini sesuai dengan pendapat bahwa penerapan aplikasi android terbukti dapat meningkatkan antusiasme siswa dalam belajar (Yektyastuti \& Ikhsan, 2016). Sajian materi menggunakan perpaduan teks, gambar, dan video dapat mengakomodasi gaya belajar mahasiswa yang beragam. Dengan demikian, mahasiswa berkesempatan mendapatkan hasil belajar yang lebih maksimal. Hal ini dikonfirmasi hasil penelitian oleh Trisyagil et al., (2020) bahwa material yang disajikan melalui media berbasis flash memudahkan siswa untuk mengakses materi, sehingga mereka mampu mendapai tujuan pembelajaran dengan baik.

Terlepas dari rendahnya hasil tes prior knowledge mahasiswa (Gambar 4), sebenarnya membuktikan bahwa SISTA dapat mengukur prior knowledge di mata kuliah sistematika tumbuhan. Manfaat adanya SISTA sebagai media tes adalah pengajar dapat mengenali tingkat prior knowledge mahasiswa, dan melakukan pemantapan sebelum pembelajaran inti dimulai. Hal ini karena prior knowledge yang mantap dapat meningkatkan proses memori dan mendorong mahasiswa dalam perolehan pengetahuan baru (Wade \& Kidd, 2019). Pemantapan prior knowledge tersebut berguna untuk kelancaran proses pembelajaran, mencapai tujuan pembelajaran, dan memaksimalkan hasil belajar mahasiswa. Hal yang paling penting adalah bahwa melalui tes prior knowledge, potensi munculnya miskonsepsi pada mahasiswa dapat diminimalisir.

Penggunaan aplikasi mobile sebagai bagian dari pembelajaran di bidang biologi tentunya semakin diminati. Hal ini karena proses pembelajaran biologi sering dihadapkan pada materi yang tidak dapat divisualisasikan secara langsung sehingga sulit dipahami siswa (Mukti \& Nurcahyo, 2017). Tak terkecuali pada mata kuliah sistematika tumbuhan. Aplikasi mobile yang sering dikembangkan selama ini adalah aplikasi mobile sebagai media pembelajaran interaktif (Darmawan \& Nawawi, 2020) dan lembar kerja siswa (Arizen \& Suhartini, 2020) untuk menunjang model pembelajaran tertentu. Tujuan pengembangan aplikasi pun beragam, misalnya untuk meningkatkan hasil belajar siswa (Amalia et al., 2020); untuk meningkatkan motivasi siswa (Trisyagil et al., 2019); dan meningkatkan critical thinking siswa (W. P. Sari \& Ma'rifah, 2020). Melalui penelitian pengembangan SISTA ini dibuktikan bahwa mobile learning berbasis android ternyata juga dapat dikembangkan sebagai media tes untuk mengetahui prior knowledge mahasiswa.

SISTA sebagai media tes berbasis android memberikan kenyamanan bagi mahasiswa dalam mengerjakan tes, dan memberikan kemudahan bagi pengajar untuk menerima dan menganalisis hasil tes mahasiswa. Melalui media tes ini, mahasiswa juga dapat memantapkan prior knowledge melalui video dan animasi yang terdapat dalam SISTA. Kemudahan akses dan interaktifnya tampilan tersebut menjadikan media tes berbasis android ini menyenangkan. Tentunya, pengembangan aplikasi mobile berbasis android sebagai media tes perlu memperhatikan tujuan penggunaan, kesesuaian materi ajar, sasaran pengguna, dan sistem pendukungnya.

\section{SIMPULAN}

Pengembangan SISTA, sebuah aplikasi mobile berbasis android dinyatakan valid dan dapat digunakan sebagai media tes prior knowledge mahasiswa. Hal ini berdasarkan asil validasi ahli yang secara keseluruhan menunjukkan persentase $96,19 \%$. Hasil uji keterbacaan oleh mahasiswa terhadap SISTA juga menunjukkan persentase $90,27 \%$ sehingga dapat dinyatakan bahwa SISTA valid tanpa revisi. Uji penerapan SISTA di kegiatan pembuka pada mata kuliah sistematika tumbuhan juga menunjukkan bahwa SISTA dapat digunakan sebagai media tes prior knowledge. SISTA sebagai media tes berbasis android memberikan kenyamanan bagi mahasiswa dalam mengerjakan tes, dan memberikan kemudahan bagi pengajar untuk menerima dan menganalisis hasil tes mahasiswa. Pengembangan SISTA lebih lanjut memungkinkan SISTA dilengkapi dengan fitur lain sehingga SISTA tidak hanya 
menjadi media tes prior knowledge, tapi juga media yang dapat di intergasikan dalam seluruh kegiatan pembelajaran.

\section{UCAPAN TERIMA KASIH}

Penelitian ini didanai oleh Direktorat Riset dan Pengabdian Masyarakat Direktorat Jenderal Penguatan Riset dan Pengembangan Kemeterian Riset, Teknologi, dan Pendidikan Tinggi sesuai kontrak Penelitian nomor: 021/SP2H/LT-MONO/LL7/2020. Terima kasih juga kepada Kopertis Wilayah VII dan Lembaga Penelitian dan Pengabdian Masyarakat Universitas 17 Agustus 1945 Banyuwangi.

\section{DAFTAR PUSTAKA}

Ali, S. M., \& Ahmad, M. T. (2014). Scope and impact of android application in education sector. Chronicle of the Neville Wadia Institute of Management Studies \& Research, 284-290. http://www.nevillewadia.com/images/Cronicle2015/Prof.-Shaikh-Mohammad-Ali15.pdf

Amalia, I. R., Rahayu, E. S., \& Martin, P. H. (2020). The development of Gymnospremae interactive media android based with the discovery learning to improve student learning result on plantae subject in senior high school. Journal of Biology Education, 9(1), 20-29. https://doi.org/10.15294/jbe.v9i1.36866

Arizen, A., \& Suhartini, S. (2020). Mobile learning student worksheet based on socio-scientific-issues: Enhancing students' scientific literacy skills in biology. JPBI (Jurnal Pendidikan Biologi Indonesia), 6(1), 15-24. https://doi.org/10.22219/jpbi.v6i1.11196

Asghar, M. Z., Sana, I., Nasir, K., Iqbal, H., Kundi, F., \& Ismail, S. (2016). Quizzes: Quiz application development using android-based MIT APP inventor platform. International Journal of Advanced Computer Science and Applications, 7(5), 43-54. https://thesai.org/Downloads/Volume7No5/Paper_8Quizzes_Quiz_Application_Development_Using_Android.pdf

Baek, Y., Xu, Y., Han, S., \& Cho, J. (2015). Exploring effects of intrinsic motivation and prior knowledge on student achievements in game-based learning. The Smart Computing Review, 5(5), 368-377. https://doi.org/10.6029/smartcr.2015.10.001

Clement, J. (2020). Number of available applications in the google play store from December 2009 to June 2020. Www.Statiska.Com.

Darmawan, H., \& Nawawi, N. (2020). Pengembangan media pembelajaran interaktif dan lembar kerja siswa pada materi virus. JPBIO (Jurnal Pendidikan Biologi), 5(1), 27-36. https://doi.org/10.31932/jpbio.v5i1.573

Dasmo, D., Dwi Astuti, I. A., \& Nurullaeli, N. (2017). Pengembangan pocket mobile learning berbasis android. Jurnal Riset Dan Kajian Pendidikan Fisika, 4(2), 71. https://doi.org/10.12928/jrkpf.v4i2.7363

Dewi, S. P., Zen, D., \& Haryani, M. E. (2019). The mapping of science teacher candidate's prior knowledge in cellular respiration topic. JPBI (Jurnal Pendidikan Biologi Indonesia), 5(3), 443450. https://doi.org/10.22219/jpbi.v5i3.10037

Hailikari, T. (2009). Assessing university students' prior knowledge: Implications for theory and practice. Helsinki University Print.

Hailikari, T., Katajavuori, N., \& Lindblom-Ylanne, S. (2008). The relevance of prior knowledge in learning and instructional design. American Journal of Pharmaceutical Education, 72(5), 113. https://doi.org/10.5688/aj7205113

Hermawan, D. P., Herumurti, D., \& Kuswardayan, I. (2017). Efektivitas penggunaan game edukasi berjenis puzzle, RPG dan Puzzle RPG sebagai sarana belajar matematika. JUTI: Jurnal Ilmiah Teknologi Informasi, 15(2), 195. https://doi.org/10.12962/j24068535.v15i2.a663

Hsu, Y., \& Ching, Y. (2013). Mobile app design for teaching and learning: Educators' experiences in an online graduate course. The International Review of Research in Open and Distributed Learning, 14(4), 118-139. https://doi.org/10.19173/irrodl.v14i4.1542

Hsu, Y., Rice, K., \& Dawley, L. (2012). Empowering educators with Google's Android App Inventor: 


\section{Jurnal Inovasi Pendidikan IPA, 7 (1), 2021 - 10}

Ifa Muhimmatin, Iis Ni'matul Jannah

An online workshop in mobile app design. British Journal of Educational Technology, 43(1), E1-E5. https://doi.org/10.1111/j.1467-8535.2011.01241.x

Johnson, A., \& Cummins. (2012). The NMC Horizon Report. 2012 Higher Education Edition. The New Media Consortium.

Kujawa, S., \& Huske, L. (1995). Strategic teaching and reading project guidebook. Oak Brook NCREL.

Mukti, I. N. C., \& Nurcahyo, H. (2017). Pengembangan media pembelajaran biologi berbantuan komputer untuk meningkatkan hasil belajar peserta didik. Jurnal Inovasi Pendidikan IPA, 3(2), 137. https://doi.org/10.21831/jipi.v3i2.7644

Nieveen, N., \& Folmer, E. (2013). Formative evaluation in educational design research. In T. Plomp \& N. Nieveen (Eds.), Educational Design Research (pp. 152-169). Netherlands Institute for Curriculum Development (SLO).

Pamungkas, A. S., Setiani, Y., \& Pujiastuti, H. (2017). Peranan pengetahuan awal dan self esteem matematis terhadap kemampuan berpikir logis mahasiswa. Kreano, Jurnal Matematika KreatifInovatif, 8(1), 61-68. https://doi.org/10.15294/kreano.v8i1.7866

Pertiwi, W. K. (2020). Penetrasi internet di Indonesia capai 64 persen (R. K. Nistanto (ed.)). Kompas. https://tekno.kompas.com/read/2020/02/20/14090017/penetrasi-internet-di-indonesia-capai-64persen

Safitri, I., Pasaribu, R., Simamora, S. S., \& Lubis, K. (2019). The effectiveness of android application as a student aid tool in understanding physics project assignments. Jurnal Pendidikan IPA Indonesia, 8(4), 512-520. https://doi.org/10.15294/jpii.v8i4.19433

Sari, A. M., \& Nurcahyo, H. (2018). Improving students learning motivation through mobile learning. Jurnal Pendidikan Biologi Indonesia, 4(3), 271-276. https://doi.org/10.22219/jpbi.v4i3.6859

Sari, A. S., Hapsari, E. D., \& Widyawati, W. (2020). Effect of using an android-based module on knowledge and attitude of nursing students about the provision of transcultural nursing. Belitung Nursing Journal, 6(1), 8-13. https://doi.org/10.33546/bnj.783

Sari, W. P., \& Ma'rifah, D. R. (2020). Pengembangan LKPD mobile learning berbasis android dengan pbl untuk meningkatkan critical thinking materi lingkungan. Jurnal Pendidikan Biologi, 11(2), 49. https://doi.org/10.17977/um052v11i2p49-58

Shing, Y. L., \& Brod, G. (2016). Effects of prior knowledge on memory: Implications for education. Mind, Brain, and Education, 10(3), 153-161. https://doi.org/10.1111/mbe.12110

Sholihah, N., Wilujeng, I., \& Purwanti, S. (2020). Development of android-based learning media on light reflection material to improve the critical thinking skill of high school students. Journal of Physics: Conference Series, 1440, 012034. https://doi.org/10.1088/1742-6596/1440/1/012034

Suma, K., Sadia, I. W., \& Pujani, N. M. (2018). Investigating 12th-grade students' prior knowledge of static electricity concepts. International Journal of Environmental \& Science Education, 13(2), 163-172. http://www.ijese.net/makale_indir/IJESE_2016_article_5a9bfc903dd2f.pdf

Surata, I. K., Sudiana, I. M., \& Sudirgayasa, I. G. (2020). Meta-analisis media pembelajaran pada pembelajaran biologi. Journal of Education Technology, 4(1), 22. https://doi.org/10.23887/jet.v4i1.24079

Svinicki, M. (2012). What they don't know can hurt them: The role of prior knowledge in learning. Essay on Teaching Excellence, 5(4), 220-227.

Thiagarajan, S., Sammel, D. D., \& Sammel, M. I. (1974). Instructional development for training teachers of exceptional children. Indiana University.

Trisyagil, T., Ahmadi, F., \& Kustiono, K. (2019). The development of flash-based media in project based learning for English subject to increase students' motivation and achievement at senior high school. Innovative Journal of Curriculum and Educational Technology, 9(2), 48-56. https://doi.org/10.15294/ijcet.v9i2.36301

Wade, S., \& Kidd, C. (2019). The role of prior knowledge and curiosity in learning. Psychonomic Bulletin \& Review, 26(4), 1377-1387. https://doi.org/10.3758/s13423-019-01598-6 


\section{Jurnal Inovasi Pendidikan IPA, 7 (1), 2021 - 11}

Ifa Muhimmatin, Iis Ni'matul Jannah

Walsh, K. (2015). Mobile learning in medical education. Ethiopian Journal of Health Sciences, 25(4), 363-366. https://doi.org/http://dx.doi.org/10.4314/ejhs.v25i4.10

Widiansyah, A. T., Indriwati, S. E., Munzil, M., \& Fauzi, A. (2018). I-invertebrata as an androidbased learning media for molluscs, arthropods, and echinoderms identification and its influence on students' motivation. Jurnal Pendidikan Biologi Indonesia, 4(1), 43.

https://doi.org/10.22219/jpbi.v4i1.5476

Yektyastuti, R., \& Ikhsan, J. (2016). Pengembangan media pembelajaran berbasis android pada materi kelarutan untuk meningkatkan performa akademik siswa SMA. Jurnal Inovasi Pendidikan IPA, 2(1), 88. https://doi.org/10.21831/jipi.v2i1.10289 